\title{
THE PORTICO OF THE CHURCH OF ST. FRANCIS IN URBINO: A DIGITAL MAP FOR MONUMENTS
}

\author{
Laura Baratin $^{\mathrm{a}}$, Monica Giuliano ${ }^{\text {a }}$, Giovanni Checcucci ${ }^{\mathrm{b}}$ \\ aDiSBEF - University of Urbino, Campus Scientifico - „E. Mattei“, 60129 Urbino, Italy laura.baratin@uniurb.it, \\ monicagiuliano@hotmail.it \\ b ABC General Engineering s.r.l., 50132 Florence, Italy giova56@hotmail.com
}

\begin{abstract}
KEY WORDS: 3D MODEL, CONSERVATION, HISTORICAL MONUMENTS, DIGITAL MAP, PHOTOGRAMMETRY, LASER SCANNER
\end{abstract}

\begin{abstract}
:
This paper describes the preliminary study for restoration works on the portico of the Church of St. Francis in Urbino. The aim of this study is to develop models used for restoration works on the surfaces of the portico, based on a prior architectural survey using different methodologies. The research project was carried out in 2 phases: during the first phase quantitative data were obtained by means of formal-geometric surveys and during the second phase qualitative data were obtained by developing models. Results were diversified according to needs and the methods used in order to create a "digital map of the monument" in its context. In the last phase, the various methodologies were analysed and compared in order to evaluate their accuracy, convenience (in terms of times and costs) and application limits.
\end{abstract}

\section{INTRODUCTION}

One of the most important presuppositions of conservation is the respect afforded not only to the work of art but also to the historical data relating to the same, thus considering the work of art in its diachronic evolution, by interpreting and recognizing the building as a whole.

Conscious choices may in this way be made, and only with correct documentation is it possible to conserve and allocate new functions to architectural monuments.

The project entailed enormous responsibilities and was handled in an objective, scientific and correct manner, using all the tools of knowledge available, from historical analysis to metric surveys, from topography to the study of materials and problems of degradation, using a combination of professional skills and expertise.

The problem of survey and representation in restoration and conservation of buildings has become increasingly important over the years since it is seen as a means of investigating and organizing data in order to understand an architectural work or archaeological site.

Metric data are undoubtedly represent the first level of knowledge so that the scope was to quantify the data in a specific space.

Once data have been gathered, they may be used in other fields, as support for qualitative or historical-typological data for example and as a basis for the management of protection and planning, with the use of appropriate tools.

Survey and representation of buildings, using different methodologies and tools, means bring to the fore an activity which today involves various operators and must be interpreted by means of clear and common symbols, signs and graphs.

In these research activities as a whole, the survey is an "open system of knowledge" that ranges from the details of the single element to the organism as a whole, analysed constantly with respect to its environmental context.

The survey techniques are described in order to obtain a correct and metrically accurate representation of the building, taking into account the quality and possibility of verifying the survey in terms of interpretation, evaluation and representation of the object.

The survey must be structured as a set of differentiated and organically linked techniques and must be organised in phases, with operations ranging from general to detailed evaluations*.

Results were diversified according to needs and the methodologies used in order to create a "digital map of the monument" in its context, used as a basis to develop the following aspects:

$\rightarrow$ control and monitoring of the transformations that take place in both the natural and urban environment due to the actions of man and/or nature;

$\rightarrow \quad$ preventive surveys on monuments in highly urbanized areas;

$\longrightarrow \quad$ simulation of interventions on 3D models.

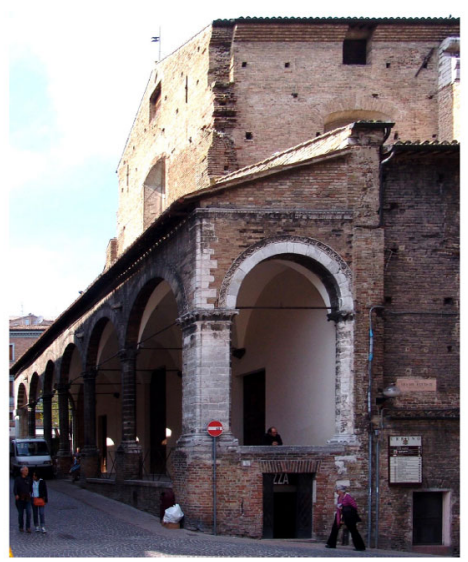

Figure 1: View of the Portico of the Church of St. Francis in Urbino

* BIANCHINI M., Manual of digital documentation and survey in archaeology, Rome 2008, page 9-20. 


\section{SURVEY AS CARTOGRAPHIC BASE TO SUPPORT RESTORATION}

In this sense, the survey must be considered as a field that makes use of all and any sciences and techniques that may help to interpret, measure and analyse the evident and hidden morphological, material and structural aspects of an object.

Definition in object rendering may in this may be directly associated to an investigation of the following phases:

1) Topographic survey in order to determine the geometric reference structure with respect to detailed surveys (photogrammetry and laser scanner), guaranteeing the planned level of precision of the survey and include the following:

a) construction of a topographic framework network by means of a total station;

b) construction of networks, anchored to the previous network, which metrically locate the details ensuring the topographic basis for the survey of points that are not accessible to direct readings as well as supporting points for photographs;

c) execution of topographic branching anchored to the previous networks, to determine the peripheral points not accessible to the polygons;

d) topographic determination of supporting points with respect to the photographic and/or photogrammetric shots;

e) accurate planimetric and altimetric compensation of topographic readings;

2) 3D Scanning. This entails acquisition of metric and deformed data by means of a laser ray surveying device. The scanning sensor, which is mounted on a motorised base, generally works within a horizontal range of $360^{\circ}$ and a vertical range of $180^{\circ}$, and records all the visible architectural points (with respect to the scanning centre), at an angle which may be adjusted by the user. As in the case of topographic surveys carried out with total station, this survey system must be collected to a polygonal network, but with a higher number of points entered and recorded. A 3D point cloud is obtained which precisely reproduces the state of the object, and permits solid modelling. This technique may be used for all elements that are difficult to access or measure and may be considered as an experimental approach, verifying its quality, times and costs.

3) Photogrammetric Surveys These are used to construct 3D models which are useful for rendering internal surfaces and also provide accurate complete documentation of the actual conditions. $6 \times 6 \mathrm{~cm}$ and/or $24 \times 36 \mathrm{~mm}$ professional cameras and/or semi-metric mono-cameras, which are suitable for $6 \times 6$ $\mathrm{cm}$ photogrammetric rendering, or the more commonly used digital cameras, may be used. Shots should be taken at a distance compatible to the rendering scale, with horizontal and vertical overlapping of the strips by at least $10 \%$ and successive cataloguing of photograms and models (including the orientation data of the same) and, in any case within the limits permitted by the morphology of the places.

4) Photographic surveys and digital photomaps. High resolution semi-metric and/or digital and professional cameras are used. A sufficient number of shots should be take to cover the entire survey area, on a general and detailed scale. The survey will be useful both for general documentation and to take digital photomaps and digital rectifying mosaics, with specific software using topographic and 3D scanner points.

5) Processing of data and line rendering. In the first phase calculations are performed to minimize data acquisition errors (accurate compensation of polygons), standardize data (rototranslations) and convert all the data to numeric format (digital). In the second phase the data acquired are rendered with the definition suited to the representation scale in question according to the methods and printouts used.

\subsection{Survey Phases}

Because of the particular features of the structure and the fact that it is located in the city centre, the study and survey project of the structures of the portico required a great deal of work, both to acquire and process data. Work was carried out in two separate phases:
1) Data acquisition:
$\rightarrow$ Topographic survey
$\rightarrow$ Photogrammetric survey
$\rightarrow$ Laser scanner survey
2) Data processing:
$\rightarrow$ Rectification and construction of photomaps
$\rightarrow$ CAD processing of photomaps
$\rightarrow$ Processing of a number of photogrammetric shots with Image Master
- Processing of laser scanner data with Z-Map and Rap- idForm 2004

\subsubsection{Survey Phases: data acquisition}

Architectural findings were measured above all by means of two techniques which are widely used in indirect surveys: total station and monoscopic photogrammetry

One day's work was required to survey the architectural complex using the following tools:

1) Electronic total station Topcon 9001A, angle precision: 1", telemeter: $5 \mathrm{~mm}$ without prism, LD laser pointer, data processing software: Mercurio (survey management) and Meridiana (topographic calculations);

2) Sony non metric camera, specifications: DSC-F828, Zeiss lens, focal length adjusted at $4.44 \mathrm{~mm}$ and 8 Megapixel sensor.

The topographic survey of the three facades was carried out with the same number of stations $(\mathrm{S} 1, \mathrm{~S} 2, \mathrm{~S} 3)$ for a total of 62 points.

The photogrammetric survey, in particular on the outdoor facades to be restored, was carried out by anchoring the photographic shots at 34 of the 64 points read with the topographic instrument.

The frames, one respectively for the North and South facades and 6 for the Western façade, were taken without positioning targets and rendered by means of reference monographs.

A second photogrammetric survey was later carried out on the Southern façade, on which a detailed survey was then carried out, in order to process the data with Image Master and compare this with the other methodologies which will successively be described. In this phase, frames of the details were also taken (capitals, arches, column bases) in order to ensure more accurate readings for the CAD drawing.

The laser scanner survey was carried out with a Topcon GLS1550 laser using time of flight technology (TOF) whereby the distance is calculated by measuring the time from when the laser impulse is transmitted by the instrument, to its return after being reflected on the surface. The Topcon GLS-1500 measures a mesh which is dense with points, known as a "cloud" with scanning speed of 30.000 points per second and maximum capacity of $330 \mathrm{~m}$. In addition, five stations were positioned and the points read were based on the physical details of the object. 


\subsubsection{Survey Phases: data processing}

In the first data processing phase, the frames were firstly "rectified", in other words the radial"* and linear*** distortions produced by the camera were corrected.

Photographic rectification makes it possible to modify a photograph so as to simulate the shot with the plane of the sensor of the camera parallel to a reference plane chosen on the photograph, giving a central perspective. The rectified image corresponds to a façade when the object is planar. In the case of typically architectural objects, consisting of different parallel planes it is necessary to scale the sections on the various planes differently using measures which are known in advance. Different techniques and data are therefore required to produce a rectified image:

-geometric techniques: using horizontal and vertical lines -analytic techniques: using known or distant coordinate points The rectified image is then scaled appropriately and becomes a metric representation that may be used, in other words, to obtain sizes and distances. ${ }^{* * * *}$

An analytic procedure using Archis 2D Pro software was used, which makes it possible to create frames by correcting a number of unknowns in the distorted image such as rotation, translation and scale factor. The only exception is the North façade of the portico which was rectified with a geometric procedure since the topographic points were not reliable and unsatisfactory for a homographic transformation with the analytic procedure.

The input data used for rectification in analytic mode were the 34 topographic points represented in the reference monographs which were appropriately matched on each frame. In view of the fact that some points read topographically were not reliable, it was also necessary to refer to other points obtained from laser scanner data.

The output data provided good rectification with an estimated error of no more than $6 \mathrm{~mm}$. The images obtained were then, "mosaiced" with the same software, reconstructing photomaps of each view examined. The sections processed in this phase were, as far as possible, only flat surfaces, considering that the three-dimensional nature of the octagonal columns of the portico, would have produced considerable distortion. To resolve the problem, the $3 \mathrm{D}$ elements subject to significant variations were processed with laser scanner data.

The survey data obtained from the total station and orthophotomosaics were imported to CAD. Considering that the photogrammetric process requires a reference system parallel to the surfaces analysed, it was necessary to carry out rototranslations from the global reference system and scale the image in its original dimensions, in order to position each façade correctly. In this way, all the data refer to a global system and may be managed at any time through a territorial computerised system.

Finally, even without working in 3D environment, it was possible to reconstruct the progress of the portico, anchored at the topographic support points and create detailed views and planes, which are indispensible for obtaining information about the object and positioning the data regarding materials and the condition of degradation.

As previously mentioned, additional photogrammetric surveys processed with Image Master were carried out on the Southern

** Radial distortions: due to the geometric characteristics of the lens, the further the object is from the focal centre the greater distortion will be.

*** Linear distortions: due to the position of the shot plane with respect to the object.

**** $\quad$ Bianchini M., op. cit., pages 156-158. façade of the Portico where conditions were more favourable for this type of experimentation.

Image Master Pro is a photogrammetric software which processes 3D data obtained from stereo images, and generates orthophotos and 3D models. During processing, the limits of photogrammetric systems in general and of this system in particular, were identified. Despite the fact that all photogrammetric systems process 3D data, they do not permit stereoscopic orientation, and in fact the photograph pairs are oriented in monoscopic mode and this introduces an error margin that with traditional stereo restitution equipment is undoubtedly lower, in that the latter permit orientation in stereoscopic mode. Moreover, in the specific case of the Image Master, when the polylines or breaklines are defined on the model, the system permits both self-correlation and manual matching; considering however that in the first case it is very difficult to recognise uniform points because self-correlation entails a high margin of error since it is tied to contingent factors such as morphology and above all, the nature of the surfaces, in some cases it is preferable to opt for manual matching. During orientation, the software operates according to strictly photogrammetric principles, giving excellent results with a very low error margin, but when creating the model the software requires various data, above all it is necessary to define the polylines when there are evident variations in height and significant discontinuity which create considerable inconsistencies between the orientation and data creation phases. It should be remembered however that this software was designed above all for teaching so that is undoubtedly less expensive that other software on the market. One of its most important advantages is that data in .wrml format may be exported, which makes it possible to use the data with other software and in remote mode.

In order to obtain an acceptable model, tests were carried out on different stereo pairs which represented the input data together with the tie points and GCPs obtained from the station. Due to the problems mentioned previously, it was necessary to process the meshes of some sections of the model separately, and these were then exported in .wrml format and processed with RapidForm 2004.

The point clouds obtained by laser scanner were initially imported and read with RapidForm, and then exported to Z-Map in .ply format where they were georeferenced on known topographic points, since the first software did not make it possible to georeference point clouds but only the surfaces. The georeferencing output data obtained showed an average error below $3 \mathrm{~cm}$. The clouds were then again imported to Rapidform where they were cleaned and filters applied, producing a mesh of small sections which were then joined and mapped. Despite the three-dimensional elements present (columns and capitals), the 3D model produced was acceptable, excluding those parts where due to objective problems (pedestrian traffic and parked vehicles) it was not possible to obtain sufficient data. 

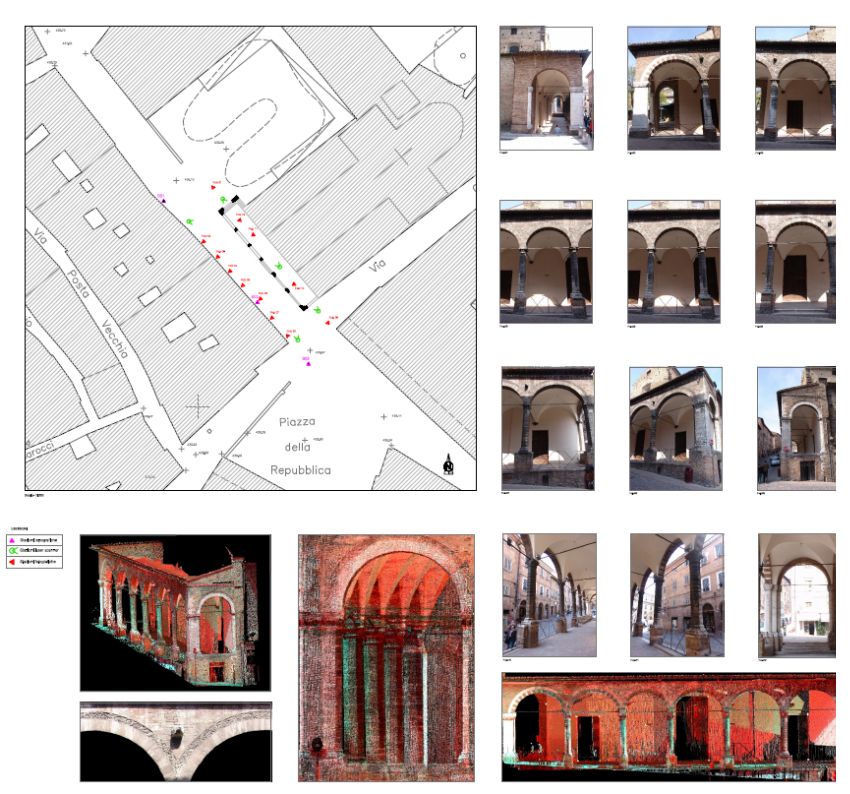

Figure 2: Survey Phase

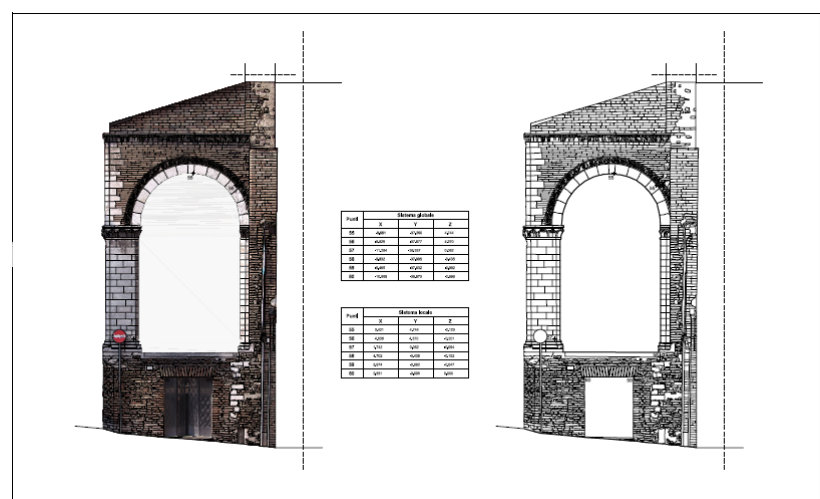

Figure 3: Survey Phase: orthophoto of the southern side elevation

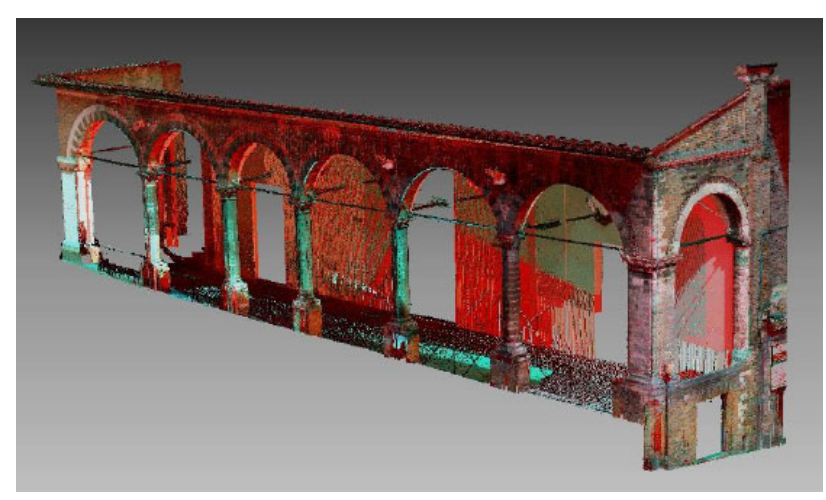

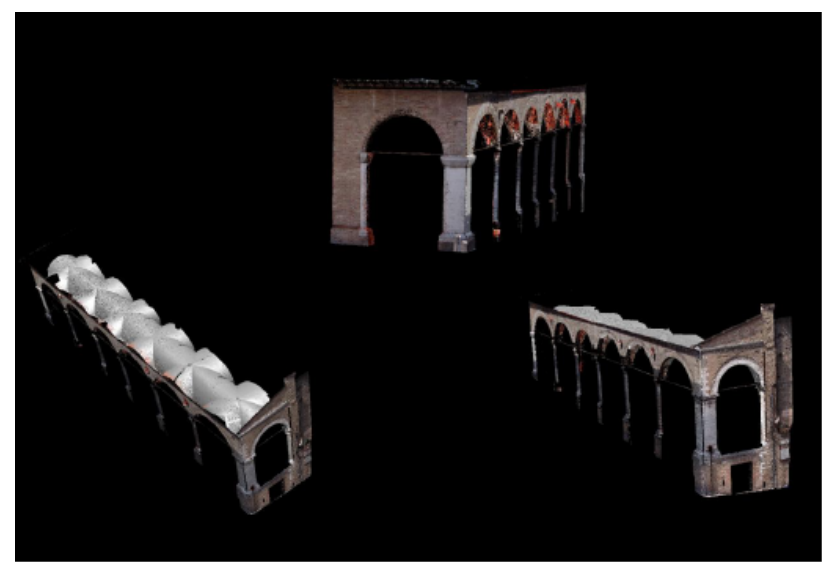

Figure 4: Survey Phase: laser scanner post processing: surface model and mapped model

\section{SURVEYS AS SUPPORT TO ANALYSIS OF MATERIALS AND DEGRADATION}

This part of the project was carried out on the three facades of the Portico, in order to process tables used as support to the restoration works.

Preliminary knowledge of a building and the materials used in an architectural structure are strictly correlated to a highly critical use of technical and operative tools which should not be separated from an analytical interpretation but must be included in the same methodological programme.

The question of survey and representation in restoration and conservation becomes is seen as a means of investigating and organising data in order to understand an architectural work or archaeological site.

Once data have been gathered, they may be used in other fields, as support for qualitative or historical-typological data for example and as a basis for protection and planning activities, with the use of appropriate tools

In this sense therefore the survey is an "open system of knowledge" that ranges from an analysis of the single elements to the organism as a whole, analysed constantly in its environmental context. ${ }^{* * * * *}$

\subsection{Analysis of Materials}

The building materials on the three sides of the portico may be grouped into two main typologies: Furlo limestone and local building bricks; limestone is used on the arcade and upper decorations, the columns and capitals, trabeation and corner blocks while the bricks are used along the section that forms the architectural framework.

White Furlo limestone has excellent technical properties: it may be cut into blocks and used as supporting elements or for decorative detailed elements. It is not have an extremely porous structure nor does it have particularly dispersed bioclasts but since it is a $\mathrm{CaCO}^{3}$ based material it is characterised by all the problems, which will be analysed in more details, that materials of

* **** Docci M., Maestri D., Il rilevamento architettonico Storia metodi e disegno, Published by Laterza, Bari 1984; Carbonara G., Restauro dei monumenti: guida agli elaborati grafici, Published by Liguori, Naples 1990; Francovich R., Parenti R. (by), Archeologia e restauro dei monumenti, Florence 1988. 
this kind have, above all when exposed to heavy pollution or acid rain. ${ }^{* * * * * *}$

\subsection{Analysis of Degradation}

The types of degradation given as examples in the materials and degradation tables may be summarized as follows:

-Erosion: removal of material from the surface by different processes. When the causes of degradation are known, terms such as "erosion due to abrasion" or "erosion due to corrosion" (mechanical causes), "erosion due to corrosion" (chemical and biological causes), "erosion due to wear" (man-made causes)" may be used. On exposed surfaces, this kind of degradation most affects sandstone and limestone as well as the mortar layers (rough coating, undulation and plastering) of surface protections (intonachino plaster finish and paint enamel). More specifically, white Furlo limestone is the material most subject to erosion caused by acid rain $(\mathrm{ph}<5,6)$ and the action of carbonic acid $\left(\mathrm{H}_{2} \mathrm{CO}_{3}\right)$ on calcium carbonate $\left(\mathrm{C}_{\mathrm{a}} \mathrm{CO}_{3}\right)$ which transforms into calcium nitrate $\mathrm{C}_{\mathrm{a}}\left(\mathrm{NO}_{3}\right)_{2}$, causing the carbonates to dissolve.

-Flaking: this type of degradation causes total or partial detachment of sections (flakes) of the original material, often close to gaps. The flakes, which consist of material which is apparently unaltered, are irregular in shape, thick and patchy. "Efflorescence" or "biological patina " may be present under the flakes. This type of degradation also affects stone materials in nature, for example manly limestone flakes are commonly found in layers exposed to weather agents. Furlo limestone is again the material with most peeling due to the action of acid rain and progression of erosion.

-Patina: An alteration strictly limited to natural modifications of the surface of the material not caused by evident phenomena of degradation, which alters the original colour of the material. Alterations induced artificially are generally known as "artificial patina". The question of treating patinas is one of the main issues of restoration since it also involves colour, to the extent that even mineral colouring and paint are subject in time to the formation of patinas that alter the colour, paint (to a lesser extent), clarity and shade (to a greater extent). When restoring existing colours therefore this type of chromatic alteration must be carefully evaluated in order to avoid the gradual transformation of the colour in the urban environment. Patinas on the limestone of the Portico are due essentially to hydrocarbon deposits (smog) that accelerate aging of the surfaces generating significant colour changes.

-Presence of oxalates: Transformation of calcium carbonate into calcium sulphate in the presence of water and polluting air gases with high sulphate content (sulphur dioxide and nitrogen oxide, the latter of which leads to the formation of soluble calcium nitrate) caused by car exhausts, domestic central heating and industrial factories. Polluting deposits on wall surfaces carried by rainwater, environmental humidity and wall capillarity lead to the formation of these hygroscopic decaying salts which rapidly disintegrate materials, producing whitish and yellowish colour changes, like those on the right hand column of the Southern façade of the Portico.

- Peeling: In the case of natural stone materials, peeled parts often have specific shapes according to the structural characteristics and texture, so that terms such as crust, flaking and exfoliation are used to describe them. Peeling may appear as the separation of the undulation from the support, the plaster from the undulation, the plaster finish from the plaster or adhesion between overlying diachronic plaster laid at different times. The most evident peeling is on the bricks on the upper section (peeling on the bottom section of the side pillar is not investigated since this will not be restored).
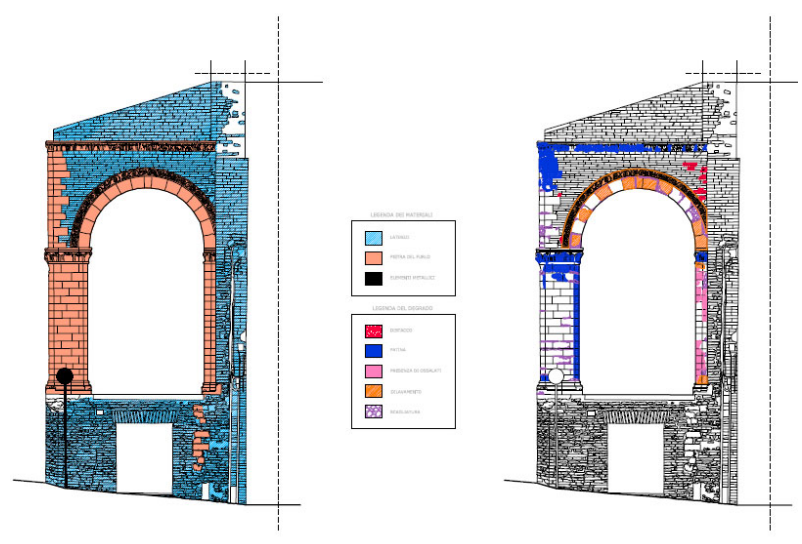

Figure 5: Analysis of materials and degradation

\section{CONCLUSION}

The main purpose of this project was the creation of a "digital map of the monument" to be used as support for the restoration of the surfaces. Different methodologies were used to produce a representation of the product that was as faithful as possible, emphasising the problem of quality and the possibility of verifying data both in terms of interpreting the object and in terms of measuring and representation. The aim was therefore not to find the most reliable system, but to develop a survey structured as a set of differentiated and organically linked techniques.

The problems encountered were the low level of precision of the topographic survey and the inadequate representation of the same in the reference monographs, which were resolved as described previously. 


\section{References}

Amoroso G.,1995. Il restauro della pietra nell'architettura monumentale. Posa in opera, degrado, pulitura, Dario Flaccovio Editore, 1995.

Baratin L., Capra A., Folloni G., Lombardini G., Russo P., Stumpo D., Trevisan C., Vittuari L., 1993. Alcune prove sperimentali per la verifica della precisione di sistemi fotogrammetrici non convenzionali. Bollettino SIFET, 1, Milano, 111-128.

Baratin L., Capra A., Folloni G., 1995. Verifica della precisione di sistemi fotogrammetrici non convenzionali: prove sperimentali sul chiostro del complesso monumentale di S.Stefano (Bologna). Atti del I Colloquio Internazionale - "La fotogrammetria per il restauro e la storia - Tecniche analitiche e digitali", Milano, 146-148.

Baratin L., Capra A., Di Thiene C., Folloni G., Guerra F., Lombardini G., Russo P., Stumpo D., Trevisan C., Vittuari L.1992. Pseudo-metric analytical photogrammetric systems: comparisons and control, Proceedings ISPRS Volume XXIXPart B5- Commission V, 372-379, Washington D.C., 1992.

Bianchini M.,2008. Manuale di rilievo e di documentazione digitale in archeologia, Roma 2008.

Carbonara G., 1990. Restauro dei monumenti: guida agli elaborati grafici, Liguori Editore, Napoli 1990.

Cairoli C.F., 1976. Archeologia e documentazione grafica, Roma 1976.

Cairoli C.F., 1994. Rilievo e analisi tecnica dei monumenti e definizione cronologica delle strutture murarie, in Rivista di Topografia Antica, IV, 1994, pp.85-90.

Ceccarelli L., 2003. "Poi che la gente poverella crebbe...": la chiesa di San Francesco d'Assisi civico "Pantheon" degli Urbinati e il convento dei frati minori conventuali in Urbino, Urbino 2003.

Cundari C., 1983. Fotogrammetria architettonica, Roma 1983.

Docci M., Maestri D., 1984. Il rilevamento architettonico Storia metodi e disegno, Editori Laterza, Roma-Bari 1984.

Francovich R., Parenti R. 1988. (a cura di), Archeologia e restauro dei monumenti, $1^{\circ}$ Ciclo di lezioni sulla ricerca applicata in archeologia, Certosa di Pontignano, Siena 23 settembre-10 ottobre 1987, Firenze 1988.

Libro dei censi e dei contratti 1286-1619, manoscritto nell'Archivio Conventuale dei Frati Minori Conventuali di Urbino.

Libro delle proposte 1750-1798, manoscritto nell'Archivio Conventuale dei Frati Minori Conventuali di Urbino.

Libro degli ordini 1756-1797, manoscritto nell'Archivio Conventuale dei Frati Minori Conventuali di Urbino.

Mazzini F., 1982. I mattoni e le pietre di Urbino, Argalìa, Urbino 1982.
Peloso D., 2005. Tecniche laser scanner per il rilievo dei beni culturali, in Archeologia e calcolatori, 16, 2005, pp.177-197.

Ricotti E.,1954. Il convento e la chiesa di San Francesco d'Assisi in Urbino, Padova 1954.

Baratin L., 2012. Survey and representation of architectural and archaeological assets: a summary of methodologies and applications. L. Baratin (Ed) Instruments and Methodologies for Cultural Heritage Conservation and Valorisation. Editor Gabbiano 2012, Ancona, pp. 85-90.

Baratin L., Grassi V., 2010. Topografia - Teoria, applicazioni, esercizi. Pitagora Editrice, 2010, Bologna.

National Center for Biotechnology Information, http://www.ncbi.nlm.nih.gov

\section{Acknowledgements}

Many thanks to the company GEOTOP s.r.l. for the availability of instruments and for their kind assistance during all phases of experimentation. 